\title{
Detección inmunohistoquímica de parafibromina en patología de paratiroides*
}

\author{
Drs. PATRICIO CABANÉ T. ${ }^{1}$, PATRICIO GAC E. ${ }^{1}$, DANIELA ARAYA C. ${ }^{2}$, \\ JOSÉ AMAT V. ${ }^{1}$, FRANCISCO RODRÍGUEZ F. ${ }^{1}$, LEONOR MOYANO S. ${ }^{2}$, \\ PABLO CAVIEDES F. ${ }^{3}$, ALVARO IBARRA V. ${ }^{4}$, IGNACIO BOZA T. ${ }^{5}$ \\ Departamento de Cirugía Hospital Clínico Universidad de Chile. \\ Departamento de Anatomía Patológica, Hospital Clínico Universidad de Chile. \\ Laboratorio de Cultivo de Tejidos-ICBM, Facultad de Medicina Universidad de Chile. \\ 4 Anatomía Patológica, Clínica Las Condes. \\ 5 Alumno Medicina Universidad de Chile. \\ Santiago, Chile.
}

Abstract

\section{Immunohistochemical detection of parafibromin in parathyroid pathology}

Introduction: The definitive diagnosis of parathyroid cancer is extremely difficult, from the clinical approach to the molecular diagnosis. A gene mutation was detected recently in patients with parathyroid cancer. It is a suppressor tumor gene called HRPT2, which codifies for a protein that participates in PAF1 complex, the parafibromin. It has been observed that the expression of this protein it's altered in parathyroid cancer, what would serve like method of diagnosis by immunohystochemistry, with a sensitivity and specificity of $73-96 \%$ and $99-100 \%$, respectively. Material and Method: The anti-parafibromin immunohystochemistry staining was made in 23 parathyroids tissue samples ( 5 adenomas, 6 hyperplasia, 7 normal and 5 carcinomas). Results: A positive pattern is observed in almost $100 \%$ of benign pathology and $100 \%$ in normal tissue. In the cases of carcinoma only 2 of 5 had a strong positivity. Conclusions: The pathological clinical correlation does not allow the association of the loss of parafibromin immunoreactivity in some unequivocal cases of parathyroid cancer. The parafibromin immunostaining does not allow to discriminate between benign or malign pathologies.

Key words: Parafibromin, parathyroid cancer, HRPT2, immunohistochemistry.

\section{Resumen}

Introducción: El diagnóstico definitivo de cáncer de paratiroides es extremadamente difícil, desde el acercamiento clínico hasta el diagnóstico molecular. Se detectó recientemente en pacientes con cáncer de paratirodes un gen supresor de tumor mutado (HRPT2), que codifica para una proteína que participa en el complejo PAF1, la parafibromina. Se ha observado que la expresión de esta proteína está alterada en los

*Recibido el 31 de julio de 2012 y aceptado para publicación el 12 de octubre de 2012.

Los autores no refieren conflictos de interés.

Correspondencia: Dr. Patricio Cabané T.

Santos Dumont 999, Santiago, Chile.

patriciocabane@gmail.com 
casos de cáncer de paratiroides, lo que serviría como método de diagnóstico por inmunohistoquímica, con una sensibilidad y especificidad de 73-96\% y 99-100\%, respectivamente. Material y Método: Se realizó tinción inmunohistoquímica anti parafibromina en 23 muestras de tejido paratiroideo ( 5 adenomas, 6 hiperplasias, 7 normales y 5 carcinomas). Resultados: Se observa un patrón positivo fuerte en casi $100 \%$ de la patología benigna y $100 \%$ en tejido normal. En los casos de carcinoma sólo 2 de 5 tenían positividad fuerte. Conclusiones: La correlación clínico patológica no permite asociar la pérdida de tinción de parafibromina en algunos casos de cáncer inequívocos. La tinción de parafibromina no permite discriminar entre patología benigna y maligna.

Palabras clave: Parafibromina, cáncer de paratiroides, HRPT2, inmunohistoquímica.

\section{Introducción}

El cáncer de paratiroides corresponde a una enfermedad poco frecuente y en las principales series reportadas con pacientes con hiperparatiroidismo primario (HPT 1rio), su incidencia es menor a un $1 \%$ en EEUU y Europa ${ }^{1,2}$. La dificultad es distinguir clínicamente, macroscópicamente y microscópicamente las neoplasias benignas de las malignas; lo que continúa siendo un desafío diagnóstico. La importancia de esta distinción es crítica para el enfrentamiento clínico-quirúrgico. Algunos autores japoneses, donde esta patología es más frecuente (5\% de los HPT 1rio), han intentado determinar factores clínicos de sospecha, determinando que niveles más elevados de PTH, Fosfatasas Alcalinas y de calcemia, junto con Densidad Ósea disminuida en el tercio distal del radio, serían factores predictores de patología maligna en hiperparatiroidismo ${ }^{3}$. El diagnóstico histológico se basa en características de invasión de cápsula o del tejido linfático y vascular, sin tener hallazgos patognomónicos que den certeza al diagnóstico. Es por esto que algunos patólogos catalogan tumores paratiroides sospechosos como equivocal carcinoma, que lleva a mantener al paciente en observación estricta. El Gold Standard en el diagnóstico de estos pacientes es la aparición de metástasis o recidiva local.

De esta forma, se han realizado esfuerzos para identificar mutaciones que apoyen el diagnóstico. Se ha descrito mutaciones de los genes Rb, PRAD1 y Ciclina 1 sin impacto real en el diagnóstico, ya que también se han encontrado en patología benigna (adenoma).

Últimamente se ha descrito el gen que codifica una proteína que participa del complejo PAF1, es la parafibromina, que actúa como parte de este complejo afectando la metilación de histonas, aumentando la capacidad de reclutar la RNA pol II. El gen se llama HRPT2 y ha sido considerado como supresor de tumor. Mutaciones específicas en él han sido detectadas especialmente en pacientes con Carcinoma de Paratiroides y en casos de adenoma asociado al Síndrome de Hiperparatiroidismo asociado a Tumor Mandibular (HPT-JT) y Quistes de Paratiroides, paciente que tienen mayor riesgo de cáncer de paratiroides $^{4,5}$.

Un estudio multicéntrico que incluye 52 casos de cáncer de paratiroides, evaluó la expresión de esta proteína por inmunohistoquímica, con el uso de un anticuerpo monoclonal anti parafibromina. Comparando con muestras de patología benigna lograron determinar que existe una marcada pérdida de la marcación de la parafibromina en los casos de cáncer. Estos autores utilizaron una escala subjetiva determinando un patrón de pérdida de tinción: Tinción difusa, pérdida de tinción focal y pérdida de tinción difusa. Asociado a la determinación de intensidad de la tinción de 1 a 3 . Según esta evaluación ellos determinaron una sensibilidad y especificidad de $96 \%$ y $99 \%$, respectivamente, en cuanto a pérdida de inmunoreactividad de parafibromina en casos de Cáncer de Paratiroides ${ }^{6}$.

Otro grupo, evidenció que la marcación nuclear de parafibromina se encuentra positiva en el $98 \%$ de los casos de Patología Paratiroidea Benigna no asociada a síndrome de HPT-JT, teniendo marcación negativa sólo 2/79 casos de adenoma paratiroideo. En los casos de patología maligna de paratiroides encontraron un $73 \%$ de marcación totalmente negativa nuclear. Existe un $20 \%$ de marcación débil y un $7 \%$ (1/15 casos) con marcación positiva nuclear ${ }^{7}$. Estos autores, a diferencia de la publicación anterior utilizaron una clasificación de intensidad de tinción en que la tinción de $>$ del $95 \%$ de las células se clasifica como tinción fuerte, $<$ del $50 \%$ de las células teñidas es una tinción débil, y la ausencia de tinción nuclear con un control interno (tejido estromal) positivo claro se clasifica como tinción negativa.

El objetivo de nuestro trabajo fue describir los patrones de tinción nuclear en tejido paratiroideo normal, patología benigna y cáncer de paratiroides, como posible método de apoyo diagnóstico en el diagnóstico diferencial.

\section{Material y Método}

Se obtuvo muestras de tejido paratiroideo normal y patológico de pacientes intervenidos por los autores. Se incluyó 5 muestras de pacientes intervenidos 
por hiperparatiroidismo primario con diagnóstico final de adenoma paratiroideo, 6 muestras de pacientes con hiperparatiroidismo secundario a insuficiencia renal con diagnóstico histológico de hiperplasia paratiroidea, 7 muestras de paratiroides normales de pacientes sometidos a tiroidectomía total (resección inadvertida) y 5 casos de cáncer de paratiroides. Todos casos intervenidos entre el año 2000 y 2006.

La técnica de tinción inmunohistoquímica fue llevada a cabo por un solo profesional, utilizando anticuerpo policlonal anti parafibromina (mouseChemicon) en una dilución de 1:100. Las muestras fueron desparafinadas y rehidratadas en batería de alcoholes, luego fueron sometidas a recuperación antigénica en buffer TRIS a $60^{\circ} \mathrm{C}$ por $60 \mathrm{~min}$. El anticuerpo primario fue incubado toda la noche a $4^{\circ} \mathrm{C}$. Se utilizó un anticuerpo secundario IgG anti- mouse asociado a HRP. Se utilizó como control positivo la tinción de muestras de tejido normal y control negativo se utilizó las mismas muestras omitiendo el anticuerpo primario.

Además se obtuvo cortes de cada muestra para tinción con Hematoxilina Eosina (H\&E) para el control histopatológico. Todas las muestras fueron analizadas por un solo patólogo (L.M.).

Se definió un patrón de tinción de porcentaje de células teñidas y de intensidad de la tinción nuclear. Se consideró como tinción positiva fuerte si las muestras presentaban $>$ del $80 \%$ de sus células marcadas, Tinción positiva débil cuando presentaba $<$ del $80 \%$ de marcación. Tinción negativa cuando existiera sólo tejido con ausencia total de marcación nuclear un adecuado control interno positivo (tejido estromal positivo). La intensidad de marcación se clasificó según la escala semicuantitativa de,+++ y +++ . Considerando el porcentaje de la mayor intensidad de marcación nuclear.

Los pacientes catalogados como carcinoma de paratiroides fueron seguidos clínicamente mediante la revisión de sus fichas clínicas y mediante llamado telefónico.

Los datos de correlación histológico, de tinción de parafibromina y seguimiento clínico fueron realizados por otro autor.

\section{Resultados}

Se realizó la tinción de parafibromina en 23 casos. Todos los casos fueron rediagnosticados histopatológicamente por un solo patólogo utilizando la tinción H\&E. De esta forma se confirmó los diagnósticos de Adenoma, Hiperplasia y tejido normal. En cuanto a los casos de carcinoma de paratiroides de rediagnosticaron como inequívocos (ante la presencia de invasión vascular o de tejidos vecinos) y sospechosos (ante presencia de invasión capsular pero ausencia de otros patrones) (Figura 1).

En la evaluación de la tinción de parafibromina se clasificó como tinción positiva fuerte $7 / 7$ casos de tejido normal, 6/6 casos de tejido hiperplásico, $4 / 5$ casos de adenoma y $2 / 5$ casos de carcinoma de paratiroides (Tabla 1).

En algunos casos de patología benigna (adenoma e hiperplasia), se obtuvo patrones de marcación heterogéneos con disminución de la marca hacia el centro de la muestra, lo que determinó una marcación más débil. De hecho el caso de adenoma catalogado como tinción positiva débil corresponde a un caso de tejido con claro daño por congelación, ya que había sido utilizado en biopsia contemporánea.

Los casos de cáncer de paratiroides presentaron

Tabla 1. Tejido paratiroideo normal y patológico clasificado según tinción positiva fuerte de parafibromina nuclear $(>\mathbf{8 0} \%$ de las células, con intensidad +++ en $\mathbf{3 0 - 5 0 \%}$ de las células)

\begin{tabular}{|lc|}
\hline Tejido & Tinción positiva fuerte \\
\hline Adenoma & $\mathbf{4 / 5}$ \\
Hiperplasia & $\mathbf{6 / 6}$ \\
\hline Normal & $\mathbf{7 / 7}$ \\
Carcinoma & $\mathbf{2 / 5}$ \\
\hline
\end{tabular}

Tabla 2. Diagnóstico histopatológico revisado y tinción de parafibromina en casos de cáncer de paratiroides

\begin{tabular}{|lllll|}
\hline Carcinoma PT & Diagnóstico HE & Positivo débil & Positivo fuerte & SEGUIMIENTO \\
Caso 1 & $\mathrm{Ca}$ & & $\begin{array}{l}+++50 \% \\
\text { heterogéneo } \\
+++30 \%\end{array}$ & Fallece por enfermedad \\
Caso 2 & Sospecha & & & 3 años libre de enfermedad \\
Caso 3 & $\mathrm{Ca}$ & $+10 \%$ & & $\begin{array}{l}\text { Fallece por rotura de AAA } \\
\text { Sin recidiva (3a) }\end{array}$ \\
Caso 4 & Sospecha & $+10 \%$ & 3 años libre de enfermedad \\
Caso 5 & Sospecha & $++30 \%$ & 1 año libre de enfermedad \\
\hline
\end{tabular}



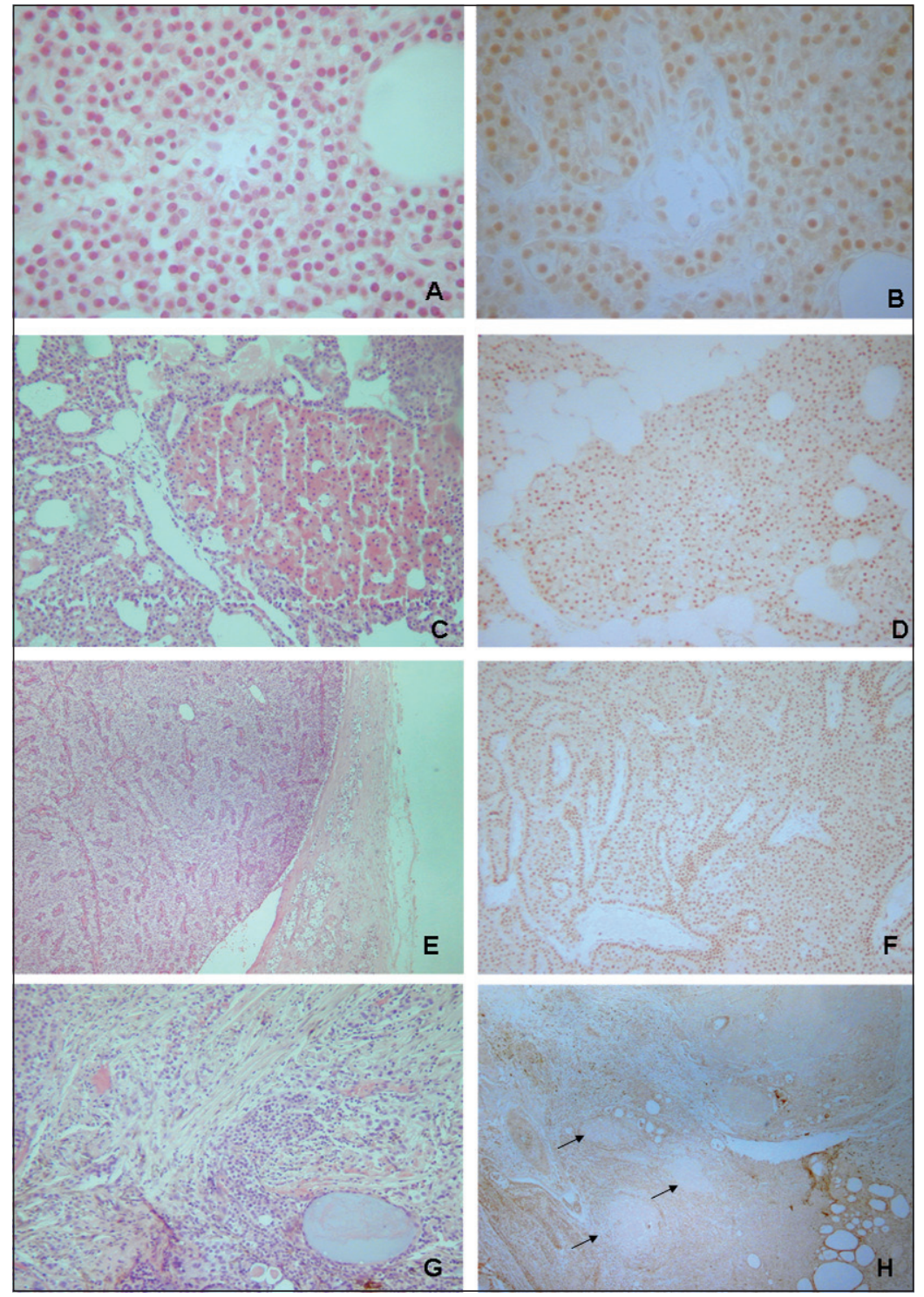

Figura 1. Tinción Hematoxilina Eosina y Tinción inmunohistoquímica Parafibromina en tejido paratiroideo. A y B corresponde a tejido PT normal - PFM 100\% $(+++100 \%) 40 X, C$ y D corresponde a tejido hiperplásico con foco oxifílico - PFM 100\% (+++ $30 \%) 20 X$, E y $\mathbf{F}$ corresponde a Adenoma de células claras - PFM $+100 \%(+++50 \%) 20 X, \mathbf{G}$ y $\mathbf{H}$ corresponde a carcinoma de paratiroides con intensa desmoplasia, invasión capsular y de tejido circundante. La tinción PFM es heterogénea con focos completamente negativos (flechas) 20X. una marcada disminución del porcentaje total de células marcadas y de la intensidad de la tinción como se detalla en la Tabla 2. Llama la atención la heterogeneidad de la tinción, presentando áreas completamente negativas y otras con tinción de mayor intensidad $(+++)$ (Figura 2). Así mismo fue llamativo encontrar áreas con patrón histopatológico inequívoco de invasión con marcación positiva $100 \%(+++)$ (Figura 3).

Al realizar la correlación clínico

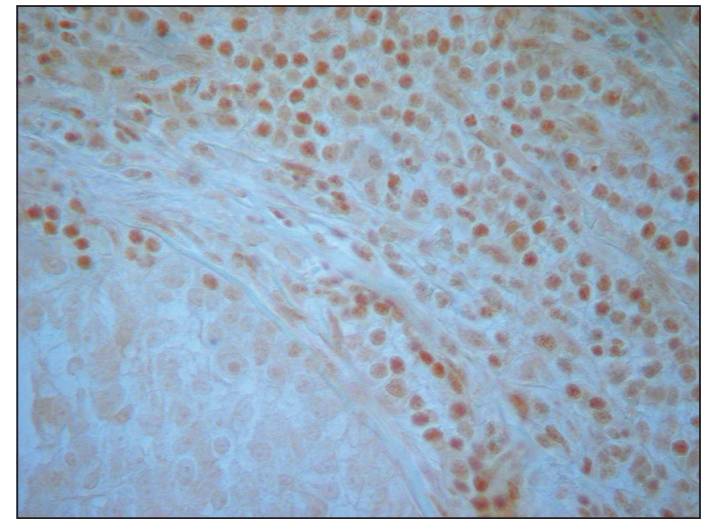

Figura 2. Patrón característico de pérdida focal de tinción nuclear en caso de cáncer de paratiroides inequívoco. (40x). 

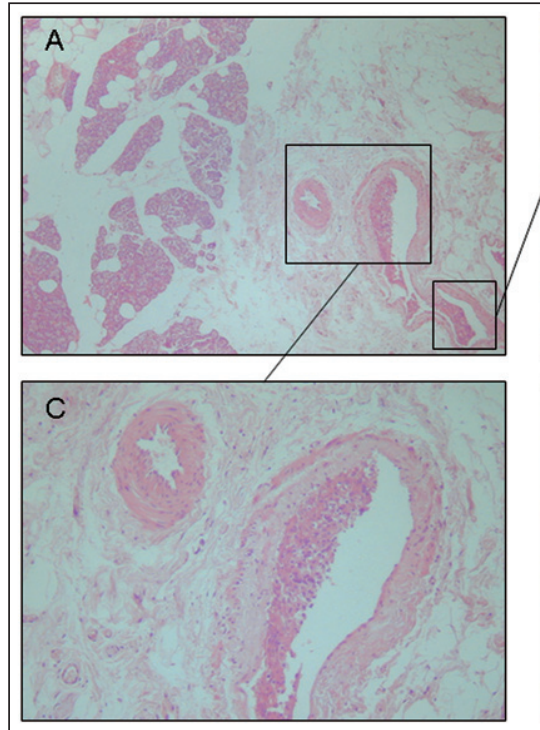

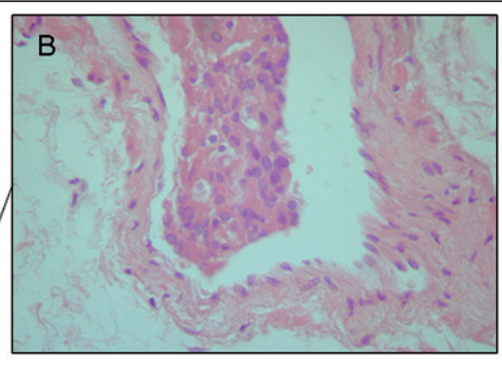

D
Figura 3. Caso de carcinoma de paratiroides. En A se aprecia el tejido paratiroideo indistinguible de la patología benigna, pero existe invasión capsular categórica, B y $\mathrm{C}$ son aumentos del trombo tumoral (40X). En D se observa tinción positiva del trombo tumoral con control interno positivo (tinción de endotelio vascular - flecha). patológica (Tabla 2) podemos ver que los casos rediagnosticados como cáncer de paratiroides inequívoco han tenido evoluciones variables, un paciente falleció por su enfermedad lo que confirma el diagnóstico y el otro paciente no ha presentado recidiva en 3 años de seguimiento.

\section{Discusión}

Existen reportes previos de detección IHQ de PFM en Patología PT, que son muy optimistas en cuanto a la posible utilización de esta tinción en diagnóstico diferencial de patología maligna.

Nuestros resultados apuntan a una clara tendencia a la negatividad focal o marcación débil, lo que podría apoyar el uso en diagnóstico diferencial. Sin embargo, también observamos casos inequívocos de cáncer de paratiroides con focos de gran agresividad (invasión vascular) con tinción máxima $(+++)$.

Existen diferencias en los parámetros arbitrarios utilizados en la categorización de la tinción, en los distintos grupos.

Desde el punto de vista técnico hay que tener especial cuidado en considerar el tipo de muestra, y a qué proceso ha sido sometido. Por ejemplo, biopsia contemporánea por congelación previa que pueda dañar el tejido y alterar la eficiencia de la inmunohistoquímica.

En suma, la tinción de PFM es claramente positiva en casos de patología benigna, con patrón de expresión difuso $100 \%$ y gran intensidad de la marca $(+++)$. En los casos de cáncer disminuye la intensidad y existe un patrón heterogéneo con focos claramente negativos. Sin embargo, áreas de alta agresividad tienen marcación positiva intensa, lo que quita validez al método en su aplicación en diagnóstico diferencial y pronóstico.

\section{Referencias}

1. Shane E, Bilezikian JP. Parathyroid Carcinoma: A review of 62 patients. Endocrine Rev. 1982;3:218-26.

2. Cohn K, Silverman M, Corrado J, Sedgewick C. Parathyroid Carcinoma: the Lahey Clinic experience. Surgery 1985;98:1095-100.

3. Chen Q, Kaji H, Nomura R, Sowa H, Yamauchi M, Tsukamoto T, et al. Trial to predict malignancy of affected parathyroid glands in primary hyperparatyroidism. Endocrine J. 2003;50:527-34.

4. Shattuck T, Välimäki S, Obara T, Gaz RD, Clarck OH, Shoback D, et al. Somatic and Germ-Line Mutations of the HRPT2 Gene in Sporadic Parathyroid Carcinoma. NEJM 2003;349:1722-9.

5. Juhlin C, Larsson C, Yakoleva T, Leibiger I, Leibiger B, Alimov A, et al. Loss of parafibromin expression in a subset of parathyroid adenomas. Endocrine-Related Cancer 2006;13:509-23.

6. Tan M-H, Morrison C, Wang P, Yang X, Haven CJ, Zhang $\mathrm{C}$, et al. Loss of Parafibromin Immunoreactivity is a Distinguishing Feature of Parathyroid Carcinoma. Cl Cancer Res. 2004;10:6629-37.

7. Gill AJ, Clarkson A, Gimm O, Keil J, Dralle H, Howell VM, et al. Loss of nuclear expression of parafibromin distinguishes parathyroid carcinomas and hyperparathyroidism-jaw tumor (HPT-JT) syndrome-related adenomas from sporadic parathyroid adenomas and hyperplasias. Am J Surg Pathol. 2006;30:1140-9. 